\title{
Hemogasometria e exame físico em cordeiros mestiços: influência do estresse calórico
}

Francisco Augusto Ricci Catalano*, Isis Vieira Rodrigues, Guilherme Cazerta Lemos, Natália Machado Rahal, Juliana Regina Peiró, Leydson Formiga Feitosa, Manoel Garcia Neto, Max José de Araujo Faria Junior, Luiz Claudio Nogueira Mendes

Universidade Estadual Paulista (UNESP), Araçatuba, SP, Brasil

*Autor correspondente

e-mail: francisco.ricci@grupointegrado.br

\section{Resumo}

Objetivou-se com esse trabalho comparar as variações do perfil hemogasométrico e do exame físico de cordeiros mestiços antes e depois de um período de estresse calórico. Para tanto, foram avaliados o perfil hemogasométrico e exame físico de 12 cordeiros mestiços, lanados e com três meses. Os animais permaneceram confinados em galpão climatizado (UNESP, Araçatuba) com temperaturas médias de $28^{\circ} \mathrm{C}$ por 34 dias. No 35ำ dia de experimento os exames físicos foram realizados e amostras de sangue coletadas. Posteriormente, os cordeiros foram submetidos a um estresse calórico (EC) com temperatura de 37으, por quatro horas. Ao término do EC, os exames físicos foram repetidos e novas amostras de sangue coletadas. As variáveis comparadas foram $\mathrm{PH}, \mathrm{PCO}_{2}, \mathrm{PO}_{2}, \mathrm{HCO}^{3}, \mathrm{SO}_{2}, \mathrm{TCO}_{2}, \mathrm{TO}_{2}$, lactato, frequência respiratória (FR), frequência cardíaca (FC), temperatura retal (TR) e temperatura axila (TA); para tanto foram utilizados os equipamentos i-Stat ${ }^{\circledR}$ Portable Clinical Analyzer, estetoscópio Littman classic II e câmara Flir i60 (Flir Systems - USA). Os resultados foram submetidos à análise de variância com nível de significância $\mathrm{P}<0,05$ $\left(^{*}\right)$. A análise de variância revelou diferença significativa entre as médias das variáveis - PH (7,39 antes e 7,45 depois do estresse calórico), $\mathrm{PCO}_{2}$ (47 antes e 40 depois), $\mathrm{HCO}^{3}$ (27,9 antes e 25,9 depois), TCO 2 (29,3 antes e 27,0 depois), FR (87 antes e 141 depois) e TA (34,8 antes e 37,2 depois) - mas não foram encontradas diferenças significantes em $\mathrm{PO}_{2}$ (45 antes e 47 depois), $\mathrm{SO}_{2}$ (72,7 antes e 77,1 depois), Lactato (1,1 antes e 0,9 depois), FC (129 antes e 128 depois) e TR (39,5 antes e 39,8 depois). 0 EC dos cordeiros após o período de quatro horas pode ser evidenciado pelo aumento da $\mathrm{FR}^{*}$ e TA*; estes aumentos são interpretados como medidas compensatórias ao aumento da temperatura ambiental em animais submetidos ao EC, os quais intensificam a perda de calor evaporativa pulmonar e perda de calor tegumentar por convecção em resposta à vasodilatação periférica, mantendo a homeotermia. Neste trabalho os cordeiros foram competentes em manter a TR dentro da normalidade após o período de quatro horas, entretanto tiveram um ganho de 
0,3 ํㅡ na TR. Já a FC não foi influenciada pelo EC. A hiperventilação teve papel fundamental nas alterações encontradas na hemogasometria onde houve redução da $\mathrm{PCO}_{2}{ }^{*}$ e $\mathrm{TCO}_{2}{ }^{*}$ com aumento de $\mathrm{PO}_{2}$ e $\mathrm{SO}_{2}$, uma vez que a associação dessas variáveis e do $\mathrm{pH}^{*}$ sugerem que esses animais sofreram de alcalose respiratória, mas essa estava devidamente compensada graças à redução do $\mathrm{HCO}^{3^{*}}$, que possibilitou o $\mathrm{pH}$ sanguíneo permanecer dentro dos limites, não desencadeando uma alcalose metabólica. 0 lactato por sua vez não foi influenciado pelo EC. Conclui-se que em resposta ao EC, os cordeiros apresentaram aumento da FR, TA e TR, além de achados hemogasométricos de alcalose respiratória compensada. 